\title{
Animal Models for Study of Diabetes Mellitus
}

\author{
A. Lukačínová, B. Hubková, O. Rácz and F. Ništiar
}

Additional information is available at the end of the chapter

http://dx.doi.org/10.5772/48325

\section{Introduction}

Diabetes mellitus is a heterogeneous group of chronic disorders of carbohydrate, lipid and protein metabolism characterized by high blood glucose levels due to relative or absolute deficiency of insulin (Eiselein et al., 2004). Hyperglycemia, the primary clinical manifestation of diabetes, is associated with the development of diabetic complications. Several studies have suggested that hyperglycemia accelerates the development of chronic complications via several mechanisms, including increased aldose reductase related polyol pathway flux, increased formation of advanced glycation end-products (AGEs), activation of protein kinase $C$ isoforms, increased hexosamine pathway flux, and overproduction of reactive forms of oxygen (Brownlee, 2001). AGEs are a group of complex and heterogeneous compounds, including brown and fluorescent cross-linking substances (e.g., pentosidine), non-fluorescent cross-linking products (e.g., methylglyoxal lysine dimers), or nonfluorescent, non-cross linking adducts (e.g., carboxymethyl lysine) (Dyer et al., 1991). Increasing evidence identifies AGE formation as the critical pathogenic link between hyperglycemia and long-term complications of diabetes: nephropathy, neuropathy, and retinopathy (Wada \& Yagihashi, 2005). Therefore, another mode of diabetes treatment independent of blood glucose levels, inhibition of AGE formation, could be useful in the prevention or reduction of certain diabetic complications (Dong et al., 2010) in both main forms of the illness, Type 1 diabetes mellitus (T1D, insulin-dependent diabetes mellitus, IDDM) and Type 2 diabetes mellitus (T2D, noninsulin-dependent diabetes mellitus, NIDDM), and also in secondary forms related to gestation or other disorders.

In 2010, WHO estimated that 285 million people were living with diabetes (corresponding to $6.4 \%$ of the world's adult population). About 7 million people develop the disease each year and 3.9 million deaths were attributed to diabetes yearly (Shaw et al., 2010; Roglic \& Unwin, 2010). Current predictions estimate that the prevalence of diabetes will reach 438 million by 2030 (corresponding to $7.8 \%$ of the adult population) and that $80 \%$ of prevalent cases will occur in the developing world (Roglic \& Unwin, 2010). The increase is mainly driven by 
changes in dietary habits and low levels of physical activity (Wild et al., 2004). In the poorest countries, diabetes is more common among the better-off, but economic development quickly reverses this trend so that people from lower socioeconomic groups are more affected by diabetes; consequences are worse among the poor in all countries (Whiting et al., 2010, Blas \& Sivasankara Kurup, 2010). Diabetes mellitus and specially diabetes with chronic complications belongs to the diseases requiring huge costs (Ettaro et al., 2004).

Diabetes mellitus is a syndrome characterized by many symptoms most typical of which is hyperglycemia. T1D is $<10 \%$ of all diabetes cases, but its prevalence is constantly increasing (Green et al., 2001). This type occurs most frequently around the age of 14 years and individuals affected by this type must be treated throughout life with insulin injections (Rossini et al., 2003). Disease is the result of inflammatory islet infiltration (insulitis) and selective destruction of insulin producing $\beta$-cells (Atkinson and Eisenbarth, 2001). In general, diabetes being an autoimmune basis, T1D occurs frequently in individuals with other autoimmune diseases, especially intestinal or thyroid gland. It is strongly bound to major histocompatibility system (MHC), is dependent on $\mathrm{T}$ cells and can be modified by immunosuppression. When you start an autoimmune mechanism, exogenous factors play a role particularly of viral origin, but also antigens of the host cells based on molecular mimicry. These trigger tissue-specific immune response producing cross-reactive effector cells or antibodies that recognize self-proteins of $\beta$ cells of the pancreas (Kukreja \& Maclaren, 1999). Coxsackie B4 virus, for example, contains a sequence of 18 amino acids similar to enzyme glutamic acid decarboxylase (GAD) of pancreatic $\beta$-cells (Kaufman et al., 1992). At the same time viruses can cause subtle damage to the $\beta$-cells followed by autoimmune response against damaged $\beta$-damaged cells with sequestrated virus antigen. Other studies have identified endogenous retroviral genomes in diabetic islets, but whether the virus initiates or is only a marker of the disease remains unclear (Benoist \& Mathis, 1997). Regardless of the type of trigger are activated specific self reactive $\mathrm{T}$ cell clones against pancreatic $\beta$-cells, which then infiltrate the islets of the pancreas. It is believed that these $\mathrm{T}$ cell clones belonging to the $\mathrm{T}$ helper 1 (Th1) subset. These Th1 cells produce characteristic cytokines, such as IFN $\gamma$ and IL-2, which are considered as triggers of insulitis and destruction of $\beta$-cells of the pancreas (SuarezPinzon \& Rabinovitch, 2001). Following the massive loss of pancreatic $\beta$-cells develop severe deficiency of insulin resulting in hyperglycemia. This causes glycogenolysis in the liver, activate gluconeogenetic pathways and decreases cellular uptake of glucose in peripheral tissues (muscle and adipose). Extensive degradation of fats and oxidation of fatty acids leads to hyperlipidemia and ketosis. The essential symptoms include hyperglycemia, polyuria due to osmotic diuresis, thirst due to hyperosmolar state, weight loss due to depletion of fat reserves and negative nitrogen balance, neurotoxicity due to hyperglycemia and ketoacidosis (Eiselein et al., 2004). If patients are not treated die due to circulatory collapse and coma. When initiating therapy by exogenous insulin, but are frequent hyperglycemia, develop micro- and macroangiopathies. Therefore, in diabetic patients is increased risk for coronary heart disease, stroke, gangrene of the lower limbs, chronic kidney disease, blindness and visual disturbances, and autonomic and peripheral neuropathy. These problems reduce life expectancy by up to 25\% (Williams \& Pickup, 2004) and the most common causes of death are diseases of heart and kidney. 
In addition to people diabetes mellitus are quite often found in animals living with man (dog, cat), pets (or livestock) and laboratory animals (Malaisse \& Sener, 2008).

For eliminate ethical and logistic problems in the study of T1D in connection with the heterogeneity of outbreed human populations, have been developed so many animal models of induced and spontaneous diabetes with the possibility of more frequent sampling, biopsy and autopsy samples. In these models it is possible to breeding at a controlled heredity and study of various environmental factors in relatively large and uniform populations. Animal models have a special status in the study of pathogenesis of chronic complications of diabetes, which are considered the following mechanisms: (1) non-enzymatic glycosylation, (2) intracellular hyperglycemia with associated disturbances in the polyol pathway, (3) activation of protein kinase C (PKC) and (4) increased hexosamine pathway flux (Eiselein et al., 2004). Non-enzymatic glycosylation lead to irreversible formation of advanced glycation end products (AGEs) through the Maillard reaction, and this is probably the best studied pathogenetic factor of diabetic complications. Pathological effects of AGEs are induced by impaired function of glycosylated products and by activation of AGE receptors on endothelial cells, monocytes, macrophages, lymphocytes and mesenchymal cells. Increased risk of heart diseases in diabetics is mainly attributed to the formation of AGEs (Eiselein et al., 2004). Glycosylation of collagen type IV in basement membranes of blood vessels leads to crosslinks between interstitial proteins and lipoproteins, e.g., LDL. (Vlassara, 1996). LDL can be glycosylated and subsequently oxidized (Bucala et al., 1993). Modified LDL can then be bound to receptors of macrophages (CD36). The resulting foam cell formation and development of the fatty streak in the sub-endothelial space is the beginning of the atherosclerotic process (Ohgami et al., 2001). Since in diabetics the levels of AGEs of apoprotein B and phospholipids are several times higher as compared to nondiabetics, diabetics have a three- to four-fold higher risk of cardiovascular diseases (Bucala et al., 1994) and it is expected that non-enzymatic glycation is responsible also for vascular occlusions (Peppa et al., 2004). Other studies have attributed the importance of AGEs in hypertension, kidney pathology and erectile dysfunction in diabetics. These injuries are caused by AGEs present in the vascular matrix, where it inhibits the vasodilatory effect of EDRF (NO) and increased expression of endothelin-1, a potent vasoconstrictor (Quehenberger et al., 2000). Many of the effects of AGEs are dependent on the receptor. The best characterized receptor of AGEs is the receptor for advanced glycation end products (RAGE), which is a member of the immunoglobulin superfamily of cell membrane molecules (Stern et al., 2002). Studies in rodent models demonstrated that blocking RAGE can inhibit vascular hyperpermeability and reduced development of atherosclerotic lesion (Wendt et al., 2002). These results suggest that AGE-RAGE system may be a promising target for prophylaxis and treatment of late complications of diabetes mellitus. Hyperglycemia can cause various damages by changing polyol pathway, diacylglycerol-PKC pathway is important for develop of micro- and macro-angiopathy, and finally hexosamine biosynthetic pathway is also involved in the development of diabetic vascular complications (Eiselein et al., 2004). 
In the study of T1D is primarily used two species of laboratory animals, rat and mouse (von Herrath and Nepom, 2009). The most commonly used model is non-obese diabetic (NOD) mouse (Serreze and Leiter, 2001). Many data in the literature explains the genetics and immunology of these animals and they were identified by at least 27 genetic loci and many immunological defects (Serreze and Leiter, 2001). Their disadvantages as a model consisted of two facts. Firstly, for this model in addition to immunosuppression also other immunomodulatory interventions showed a preventive effect on diabetes (Atkinson \& Leiter, 1999), in contrast, these were ineffective in humans (Skyler et al., 2002). Second, because some of the negative factors of environment, particularly viral infections (Leiter, 1998) reduced the frequency of diabetes and often act preventively in mice (Atkinson \& Leiter, 1999), while in humans viruses are known triggers. Although the original NOD mice and congenic strains derived from them provide valuable information and is necessary to keep in mind that they are not completely appropriate alternative to studying human T1D (Greiner et al., 2001). Rats provide another model. Such are BB rats (Mordes et al., 2001), a widely studied model susceptible to autoimmune destruction of pancreatic $\beta$-cells. In some experiments also nonmammal models can be exploited due they easy handling and low economic costs.

Use of animal models in diabetes research has a long tradition. Our aim was to present an overview of animal models used in research of diabetes mellitus and highlight some technological and scientific problems associated with interpretation of carrying out these experiments in accordance with current European legislation on animal protection and exploitation of animals for experimental purposes (Ništiar et al., 2006). It is based on detailed analysis of the literature, using well-known databases such as MEDLINE ${ }^{\circledR}$, HighWire Press, PubMed and basic book, "Animal Models of Diabetes: A Primer" (Sima \& Shafrir, 2000).

Already in 1890, von Mehring and Minkowski induced in dogs by removing the pancreas acute diabetes mellitus (Minkowski, 1989). In addition to partial and the total pancreatectomy, there are also non-surgical methods to induce hyperglycemia. There are five groups of diabetogenic substances: chemical and biological agents, potentiators, peptides and steroids (van der Werf et al., 2007). Among the animal models include in particular rodents, which are especially suitable for their low cost, short generation time, inherited forms of obesity and hyperglycemia. There are known animal models to study T1D also T2D (Rees \& Alcolado, 2005; Yang \& Santamaria, 2006). Animals with spontaneous T1D have been drawn by inbreed breeds in different laboratories. In contrast, animal models of T2D are very heterogeneous. This includes not only animals with single-gene mutation, but also other types with insulin resistant syndrome and impaired pancreatic $\beta$-cells (Matteucci \& Giampietro, 2008).

More recently techniques using methods of molecular biology have produced genetically modified mouse models, including knockout and transgenic animals. Knockout animals have been defective gene in embryonic stem cells. In transgenic animals modified gene is incorporated into the pronucleus of zygote and then randomly into the genome of the animal and is transferred to the offspring. 
Diabetic animal models undoubtedly have enormous benefit in clarifying the effect of insulin and insulin therapy. They also have some shortcomings, particularly when extrapolating results to humans and diabetic complications in humans (Tesch \& NikolicPaterson, 2006) as well as some results may be misleading in the study of T1D prevention by using of model rodents (Leiter \& von Herrath, 2004). It is claimed that the rodents in this area do not adequately reflect the situation in humans (Yang \& Santamaria, 2006). Accordingly, these models and experiments will be necessary to standardize especially for prevention studies. Reliable results about the differences of pharmaceutical efficiency or survival of animals, delays and onset of disease, temporal relation of events require a very clear interpretation and repeatability of the experiment as well as the establishment of appropriate databases.

\section{Basic considerations}

Already in the Helsinki Declaration of the World Medical Association, 1964 (since been revised and amended) Rule 12 says that "to be secured by appropriate conditions, environment and care of experimental animals included in the experiment." The protection and welfare (only vertebrates) used for experimental purposes is regulated by: Council Directive 86/609/EEC, Directive 2003/65/EC, Council Decision 1999/575/EC and Council Decision $2003 / 584 / E C$. While there are considerable differences in the application of these measures in own legislation of individual countries. 23 ${ }^{\text {rd }}$ January 2006 the European Commission presented a modified and a new Action Plan for to ensure the welfare of animals in the future to a much higher level in all European Union member countries.

In 1959, zoologist William Russell and microbiologist Rex Burch presented a proposal for research on the three R: replacement, reduction and refinement (Russell \& Burch, 1959). As the replacement is considered using any technique with insensitive material that replaces the use of susceptible live vertebrate animals. For the relative replacement is considered when animals are used only in certain parts of experiment thereby minimize distress during the whole experiment. Absolute replacement is if susceptible live animals are not used at any stage of the experiment. Organ and tissue cultures represent a transition between absolute and relative replacement. Reduction is one of the methods that allow researchers to reduce the number of animals used for research without reducing the statistical significance. In terms of statistical significance is extremely important to determine the number of animals needed for certain types of biomedical research (Dell et al., 2002). The significance of the test must be such as to enable to assess the clinical significance of the monitored phenomenon. Although the difference is less, we can be made certain conclusions (trends) without the need to increase the number of animals. This is necessary to meet two basic requirements, and that the differences have a normal distribution to determine the standard deviation.

Refinement is provided by better care of the animals. Fourth R, responsibility aims at increasing the accountability of scientists using animals in experiments (Bark, 1995). This area is in the forefront in recent years. 
Report A2005 submitted consensus on animal experiments in the present. It also submitted a proposal for the basic procedures and compliance with conditions of four $\mathrm{R}$ (Perry, 2007).

Regarding diabetes mellitus is necessary to admit that the conditions regarding the extrapolation of the results of animal experiments to conditions in humans are not clearly clarified. There are neither clearly intended technical conditions for carrying animal experiments for obtaining scientific knowledge. If the technological of the performance of experiments conditions are not sufficiently clarified one cannot even assume that their moral and ethical aspects are in order. From that aspect, it is clear only that the animals were subjected to experiments at the lowest discomfort (Rees \& Alcolado, 2005).

Animal models are possible principally to divide into five groups (Hau, 2008):

1. induced (experimental) models;

2. spontaneous (genetic mutant) models;

3. genetically modified models (transgenic animals);

4. negative models (strain of animals in whom the studied disease does not occur) and

5. orphan models, describing the malfunctions that occur in the model animal, but do not occur in humans (e.g., Marek's disease, bovine spongiform encephalopathy, etc.).

Induced (experimental) models are represented by animals in which a modeled phenomenon as diabetes was induced by certain agents, e.g., chemical (alloxan, streptozotocin, cow's milk), viruses (encephalomyocarditis virus) or pancreatectomy.

The use of animals for experimental purposes is always encountered negative response from the public, especially on the basis of ethical and religious reasons. These efforts led to the gradual formation of legislation towards the protection of animals used for experimental purposes. Nevertheless these experiments have contributed significantly to the current scientific knowledge of human biology, physiology, endocrinology and pharmacology (Loew, 1996). Outputs from these experiments were often not extrapolated to humans and it has also led to efforts to reduce them and to legislation guidance and control. On the other hand it should be noted that these very often contribute to a better understanding of many biological phenomena. Science on laboratory animals can be defined as a professional field focused on issues of scientific, ethical and lawful use of animals for biomedical research, i.e. interdisciplinary science involving biological and pathobiological details for optimal scientific use of animals as models for humans or other species. In general it deals with the quality of animals as susceptible objects in biomedical research. It includes comparative biology of laboratory animals, aspects of the breeding and reproduction (cross), welfare, economy of farming, anesthesia, euthanasia ${ }^{1}$, and experimental procedures. The basic precondition for the use of animals for experimental purposes is a competence of researcher, including a solid knowledge about the biological needs, care and handling of animals.

\footnotetext{
1 "Euthanasia" in association with the termination of life in animal experiment is a widely used term which on the other side is a mistake.
} 
If the use of animals for experimental purposes is an essential condition a similarity of the animal with modeled objects in the light of studied phenomenon, i.e. concept the analogy of animal models. If the analogy is closer the possibility of extrapolation of results is much more reliable. Extrapolation is used to express to what extent can be used the results from animal experiments to humans (how are applicable to humans). In the analysis from big multinational pharmaceutical companies in 150 compounds were monitored compliance (concordance) between animal models and human subjects (Olson et al., 2000). Concordance determining the toxicity of the substances to humans if were tested in rodents and non-rodents was $71 \%$, when used only non-rodents $63 \%$ and if used only rodents $43 \%$. High concordances are detected in the cardiovascular toxicity $(80 \%)$, hematological toxicity $(91 \%)$ and gastrointestinal toxicity $(85 \%)$. Low concordances are in the neurological manifestations. Despite the high concordances in animal experiments are often reports of damages in humans by preparations of certain pharmaceutical companies. E.g., penicillin is fatal for the guinea pig, but it is well tolerated by humans, aspirin is teratogenic for cats, dogs, guinea pigs, rats, mice and monkeys, but not teratogenic for pregnant women, despite their frequent use (Mann, 1984). Thalidomide causing malformations in 10000 children did not cause birth defects in rats (Koppányi \& Avery, 1966) nor in many other species (Miller \& Strömland, 1999). The close phylogenetic or morphological similarity is not crucial for the biochemical mechanisms and physiological responses, although in many cases this is so (Beynen \& Hau, 2001). A very important difference between experimental animals and human populations is their genetic variability. Experimental animals are genetically almost identical in contrast to man exhibiting great variability. It is therefore possible to lay down precise rules for extrapolation of results from one species to another species, although in the literature have been made to certain procedures (Calabrese, 1991). Under the extrapolation is necessary to bear in mind certain mathematically expressed values, although it often looks precisely from this aspect, e.g., in determining the toxicity of certain substances or to determine of pharmacologically effective doses of drugs. In our opinion, fundamental importance is the rather in detection of toxic or therapeutic efficacy of substances. For specific determination of toxic or biologically effective dose, they should be taken in extrapolating only as a possible benchmark. Therefore, for any type of research should be borne in mind that the use of animal model does not attempt to extrapolate the main objective of the immediate outcome of the man, but looking for an answer to questions of researcher. While examining the need of experiments on animals it is first necessary to determine whether the experiment gave relevant answer to the experimenter, and whether the answer to the question enriches the current knowledge about the studied phenomenon. With this reason should be hypothesis (question) subjected to analysis before the experiment (approval of animal experiments, ethics committees, input opponency), and after publishing the results (answers to questions) and by the public opinion (responses).

Selection of animal species for the experimental purpose must be based on the greatest similarity between model object and modeling object, therefore the found results showed 
the strong concordance and therefore extrapolation was valid. It is well known that the metabolic rate in young and small animals is much higher than in large and old animals, because body size is the one of the key indicators and benchmarks for extrapolation, and precisely on the basis that have been submitted to the methods of extrapolation for the calculation of effective or toxic doses of various compounds (Hau \& Poulsen, 1988).

\section{Animal models for the study of diabetes mellitus}

Recently almost 140 years passed from the excellent experiments of Mehring and Minkowski with pancreatectomized dogs. There have been many experiments with this model on rabbits and dogs when Banting and Best came to experiment, which led to the beginning of the isolation and purification of insulin (Bliss, 1982). Dog Marjorie, who was first treated with exogenous insulin, is probably one of the most famous experimental animal in the history, comparable only with Dolly the sheep from genetic studies at the end of the last century. The early experimental models of diabetes were focused on pancreatectomized (partial or total) animals. Selection of species was more or less spontaneous. Usually used by small animals (mostly rats and mice), both because of handling or space needs and the affordable price. These experiments have often been questioned that the extrapolation to humans is appropriate from experiments on larger animals such as cats, dogs, pigs and primates (McNamara et al., 2009).

Among the non-surgical method inducing hyperglycemia after pancreatic damage with toxic substances, the most famous are streptozotocin (Junod et al., 1969) and alloxan (Lenzen \& Panten, 1988; Lenzen, 2008). Surgical and non-surgical methods are a good model for studying the consequences of chronic hyperglycemia and the development of diabetic complications (Salgado et al., 2001). Using female animals it is also possible to study the effects of hyperglycemia to the offspring (Caluwaerts et al., 2003). Problems related to control of hyperglycemia, application of insulin or oral antidiabetic drugs require further improvements of experiments (Herrera et al., 1985). It should be noted that euglycemia cannot be reached in pancreatectomized animals (Harder et al., 2003). In pancreatectomized animals also transplantation of Langerhans' islet cells was studied. Islets cells can be transplanted without capsules or in capsules that protect them from rejection (Lanza et al., 1999), either subcutaneously (Wang et al., 2011), or under the kidney capsule (Korec, 1991, Carlsson et al., 2000) or via the portal vein to the liver (Trimble et al., 1980). Transplanted animals must receive antirejection therapy (Kobayashi et al., 2008). Like in humans is a key event in many successful interventions should be carried out (how many animals to be used) so that we can draw on the basis of their results, conclusions appropriate for transplantation programs.

Rodents are commonly used models for testing the new pharmacologically active substances not only in the context of transplantation (immunosuppressives), but also with regard to therapy or prevention of human diseases. Rats and mice are commonly used in safety and effectiveness testing of new orally active compounds. These experiments also led to unexpected findings about how the PPAR $\gamma$ agonists may have a protective effect on the 
$\beta$-cells (Bonora et al., 2008). Similarly, in such experiments were also identified the effects of insulin analogues for the development of tumors (Sandow, 2009).

Experimental animals used to study of diabetes mellitus can be essentially classified into several groups (Shafrir, 2003):

1. Animals with chemically induced destruction of pancreatic $\beta$-cells:
a. Alloxan model
b. Streptozotocin (single dose)
c. Streptozotocín (more subdiabetogenic doses).

2. Animals with spontaneous autoimmune diabetes:
a. BB rats
b. NOD mice
c. Akita mice
d. LETL rats
e. Torii rats
f. LEW.1AR1/ZTM.

3. Genetically altered animals (transgenic models) with various form of diabetes

4. Insulin resistant mutants of rodents with potent diabetogenity:
a. C57BKs $d b$ mice $\left(l e p r^{d b}\right)$
b. C57BL6J $o b$ mice (lepob)
c. Yellow $\mathrm{A}^{\mathrm{v}}$ a $\mathrm{A}^{\mathrm{vy}}$ mice
d. KK mice
e. $\quad$ NZO mice
f. Zucker fa rats $\left(\right.$ lepr $\left.^{f a}\right)$ and $\mathrm{BB} /$ Wor rats
g. Zdf/Drt-fa rats
h. Wistar-Kyoto diabetic/fatty rats
i. Obese (corpulent, $c p$ ) rats of strains SHR/N-cp, LA/N-cp, SHHF/Mcc-cp and JCR.LA-cp.

5. Rodents with spontaneous diabetes of various etiology:
a. NON mice
b. WBN/Kob rats
c. ESS rats
d. BHE/Cdb rats
e. OLETF rats
f. NSY mice
g. Koletzky (SHROB) rats $\left(f a^{K}\right)$
h. Hypertriglyceridemic (HTG) rats

6. Rodents by overfeed induced diabetogenity:
a. Psammomys obesus (sand rats, gerbil)
b. Acromys cahirinus (spiny mice)
c. C57BL/6J mice 
Diabetic rodents obtained by selective crossbreeding from normal strains:

d. GK (Goto-Kakizaki) rats

e. Cohen diabetic rats (induced by diabetogenic diet rich in sucrose and poor in copper).

7. Diabetic non-rodents:
a. Primates
b. Pigs
c. Dogs
d. Cats.

\subsection{Models of spontaneous type 1 diabetes mellitus (T1D)}

The most known models of spontaneous T1D include NOD (non-obese diabetic) mice and BB (BioBreeding) rats, having a many common features with human T1D (von Herrath $\&$ Nepom, 2009). In addition to these we include here LETL (Long Evans Tokushima Leans) and KDP (Komeda diabetes prone) rats, LEW congenic rats, New Zealand white rabbits, Keeshond dogs (long haired dog of Dutch race), Chinese hamster and Celebes black apes. It should be noted that these animals are kept as inbred in laboratory conditions for many generations and gradually selected to hyperglycemia.

An excellent overview and classification of animal models of T1D is in von Herrath \& Nepom (2009):

- Spontaneous or genetically modified diabetic animals:

- Non-obese:

- NOD mice

- Akita mice

- BB rats

- $\quad$ LETL (Long-Evans Tokushima Lean) rats

- $K D P$ (Komeda diabetes prone) rats

- LEW.1AR1/Ztm-iddm rats

- Monkeys

- Keeshond dogs

- $\quad$ Some races of cats (feline models).

- Chemically induced diabetic animals:

- Non-obese:

- $\quad$ Single dose of ALX, respectively, more low doses of STZ

- Vacor (rodenticide, which acts as an antagonist of B vitamins, particularly nicotinamide), dithizone, dehydroascorbic acid, pentamidine and 8hydroxyquinoline.

- Surgically prepared diabetic animals:

- Non-obese:

- Totally pancreatectomized animals, e.g., dogs, primates, pigs and rats.

- Virus-induced models. 


\subsection{Models of spontaneous type 2 diabetes mellitus (T2D) and monogenic forms of diabetes}

T2D is a heterogeneous group of disorders characterized by insulin resistance and impaired insulin secretion, defined by elevated fasting glycemia and hyperglycemia after load of glucose. Some newer subtypes of diabetes are based on single-gene defect, called MODY (Maturity Onset Diabetes of the Young) syndromes (Vaxillaire \& Froguel, 2008), syndromes with severe insulin resistance (Semple et al., 2011) and a mitochondrial diabetes (Berdanier, 2007). In most patients, diabetes is caused by several genetic and environmental factors and disease development in all leads to chronic complications.

Animal models of T2D are complex and heterogeneous as in humans (Kaplan \& Wagner, 2006). Advances in the interpretation of the problem coming from various sources and models (ob/ob mice - monogenic model of obesity with leptin deficiency, $\mathrm{db} / \mathrm{db}$ mice monogenic model of obesity with leptin resistance, Zucker [fa/fa rats] - monogenic model of obesity with resistance to leptin; Goto Kakizaki rats, KK mice, NSY mice, OLETF rats, Israeli sand [desert] rats, streptozotocin-treated rats receiving fat diet, CBA/Ca mice, New Zealand obese mouse). In some animals, is dominated insulin resistance, compared to other it is damage of pancreatic $\beta$-cells (Cefalu, 2006). Animals with glucose intolerance and phenotypically more obese with dyslipidemia and hypertension are a good model of human T2DM. Similar to NOD mice and BB rats for T1D, selective inbreeding increases the spontaneous incidence of T2D. Most of the studies come from monogenic models of $o b / o b$, $d b / d b, f a / f a$ and agouti strains (Franconi et al., 2008).

Obesity and subsequent insulin resistance are the main triggers of T2D in humans. Due to strong similarities with humans animal models must be obese. Some strains maintain euglycemic status with a strong and sustained compensatory response to $\beta$-cells, leading to insulin resistance and hyperinsulinemia. Similarly, ob/ob mice and $f a / f a$ rats are a good example of this phenomenon. For others, such as $d b / d b$ mice and Psammomys obesus which were rapidly develops hyperglycemia and therefore $\beta$-cells are not able to maintain high levels of insulin. The study of these different animal models may be helpful in explaining why some people with morbid obesity never develop T2D while in others hyperglycemia is already at relatively mild insulin resistance and obesity (Tirabassi et al., 2004).

These models have also contributed significantly to the study of obesity (Srinivasan \& Ramarao, 2007). In 1994, Friedman with coworkers cloned ob/ob mice with a mutant gene for severe obesity (Zhang et al., 1994). Normal ob gene encodes a protein secreted by adipocytes and called leptin. In $d b / d b$ mice and $f a / f a$ rats was found mutations in the gene for the hypothalamic leptin receptor (Lee et al., 1996).

Recent classification of animals for modeling of T2D:

- $\quad$ Spontaneous or genetically modified diabetic animals:

- Obese: 
- $\quad o b / o b$ mice

- $\quad d b / d b$ mice

- KK (Kuo Kondo) mice

- $\mathrm{KK} / \mathrm{A}^{y}$ (yellow obese) mice

- $\quad$ NZO mice

- $\quad$ NONcNZO10 mice

- TSOD (Tsumura Suzuki obese diabetic) mice

- M16 mice

- Nagoya-Shibata-Yasuda (NSY) mice

- Zucker fatty rats

- ZDF (Zucker diabetic fatty) rats

- Obese-hyperglycemic Wistar Kyoto rats

- $\mathrm{SHR} / \mathrm{N}-\mathrm{cp}$ rats

- $\mathrm{SHHF} / \mathrm{Mcc}-c p$ rats

- JCR/LA- $c p$ rats

- OLETF rats

- $\quad$ eSS rats

- $\mathrm{BHE} / \mathrm{C} d b$ rats

- Koletzky (SHROB) rats

- Yucatan miniature pigs

- Sinclair miniature pigs

- Göttingen miniature pigs

- Ossabaw pigs

- Familial hypercholesterolinemic pigs (FHP)

- Obese rhesus monkeys

- Macaca fascicularis

- Macaca radiata

- Papo anobis.

- Non-obese:

- $\mathrm{WBN} / \mathrm{Kob}$ rats

- Goto Kakizaki (GK) rats

- Hypertriglyceridemic (HTG) rats

- Torii rats (SDT, spontaneously diabetic Torii)

- Torii non-obese mice C57BL/6

- ALS/Lt mice

- Non-obese mutant C57BL/6 (Akita) mice.

- With diet/nutrition induced diabetic animals:

- Cohen diabetic rats

- Psammomys obesus

- Acomys cahirinus

- Ctenomys talarum (tuco tuco)

- Guinea pigs (Cricetulus griseus)

- C57/BL 6J mice 
- Macaca mullata

- Dogs

- Cats

- $\quad$ Chinese Guizhou mini-pigs.

- Chemically induced diabetic animals:

- Obese:

- GTG (gold thioglucose)-treated obese mice

- Yorkshire and with Yorkshire crossbred strains of pigs (STZ-induced diabetes).

- Non-obese:

- Single low dose of ALX or single dose of STZ to adult rats, mice and etc.

- Neonatal STZ-treated rats.

- Surgically prepared diabetic animals:

- Obese:

- $\mathrm{VMH}$ (ventromedial hypothalamus)-damaged dietetically obese diabetic rats.

- Non-obese:

- $\quad$ partially pancreatectomized animals, e.g., dogs, primates, pigs and rats.

- Transgenic/knockout diabetic animals:

- Obese:

- $\quad \beta_{3}$ receptor knockout mice

- UCP1 knockout mice.

- Non-obese:

- transgenic or knockout mice in genes for insulin, insulin receptor and their components in the direction of insulin signaling, i.e., IRS-1, IRS-2, GLUT-4, PTP-1B and other

- PPAR- $\gamma$ tissue specific knockout mice

- Glukokinase or GLUT-2 gene knockout mice

- HIP rats (rats with overexpession of human islet amyloid polypeptide).

\subsection{Models of spontaneous type 2 diabetes mellitus - Advantages and disadvatages}

In view of advantages and disadvantages of different models of T2D animal models, we can say that:

- Spontaneous or genetically modified diabetic animals have:

- Advantages:

- Development of T2D is a spontaneous and provides genetic factors. In animals developed the similar features as in human T2D.

- Animal models are mostly inbred in which is homogeneous genetic background and environmental factors are well controllable.

- Variability of the results is minimal and requires a small number of animals. 
- Disadvantages:

- They are highly inbred, homogeneous, and often with monogenic inheritance therefore development of diabetes is strongly genetically determined versus heterogeneity in humans.

- Limited life span and the time dimension of diabetes study.

- In animals with brittle pancreas (db/db, ZDF rats, $P$. obesus, and other) is high mortality caused by ketosis and therefore need insulin treatment to prolong their life.

- $\quad$ Require more sophisticated forms of breeding purposes and care.

- With diet/nutrition induced diabetic animals:

- Advantages:

- The development of diabetes associated with obesity is the result of overfeed, as it is also in diabetes in human populations.

- Toxicity of chemical (diabetogenic) compounds to other vital organs and tissues can be eliminated.

- Disadvantages:

- Animal models often require long periods of dietary treatment.

- Not too significant hyperglycemia are after a simple dietary treatment in genetically normal animals and are therefore unsuitable for studying antidiabetogenic substances by determining of blood glucose.

- Chemically induced diabetic animals:

- Advantages:

- Selective loss of $\beta$-cells of the pancreas (alloxan/STZ), while maintaining of intact $\alpha$ - and $\delta$-cells.

- Residual insulin secretion allows animals to live without insulin therapy a relative long time.

- Ketosis and subsequent mortality is relatively low.

- They are cheaper and easier to maintain.

- Disadvantages:

- Hyperglycemia develops primarily as a result of direct cytotoxic effects on $\beta$ cells and subsequent insulin deficiency and not as a result of insulin resistance.

- Chemically induced diabetes is less stable and often occurs spontaneously regeneration of pancreatic $\beta$-cell, which is a disadvantage of long-term studies.

- In chemically induced diabetes can be toxic substance damaged other molecular structures, and may result to the general toxic effects.

- Variability of results with regard of hyperglycemia is very high.

- Surgically prepared diabetic animals:

- Advantages:

- Eliminates the cytotoxic effect of chemical diabetogenic substances to other organs and tissues.

- $\quad$ Strongly resembles regarding reduction of $\beta$-cell mass to human T2D. 
- Disadvantages:

- Technical complexity and cumbersome, postoperative procedures.

- The occurrence of certain digestive problems (as result of excision of the exocrine pancreas, amylase deficiency, etc.).

- Removal of $\alpha$-cells (glucagon producing) together with $\beta$-cells leads to problems in regulation of hypoglycemic events.

- Mortality is relatively high.

- Transgenic/knockout diabetic animals:

- Advantages:

- The effect of a single gene or their mutations on diabetes can be studied in vivo.

- Greatly facilitate the resolution of the genetic complexity of T2D.

- Disadvantages:

- Highly sophisticated and expensive procedures for production and breeding.

- Very expensive for routine screening tests.

Spontaneous T2D diabetic animals are normally obtained from animals with mutations in one or more genes that are transmitted from generation to generation (e.g., $o b / o b, d b / d b$ mice) or the selection from non-diabetic outbred animals selectively crosses over several generations (e.g., GK rats, TSOD mice). These animals have congenital diabetes with the monogenic or polygenic defects. Metabolic peculiarities may be due to a single gene defect (monogenic) with a dominant phenotype (e.g., yellow obese KK/Ay mice) and the recessive phenotype (diabetic $d b / d b$ mice, Zucker fatty rats) or may have polygenic origin (i.e. KK mice, NZO mouse) (Aerts \& Van Assche, 2006). T2D in humans is the result of interaction of different environmental factors and many genes which under certain conditions may manifest as diabetes with very contrasting symptomatology (e.g., MODY), single-gene defects with clinically overt diabetes are rare. Therefore, animals with polygenic defects are more objective for a modeling study of T2D in humans (Lofty et al., 2011).

\section{Problems of evaluation and interpretation of the results from animal experiments}

Long-term fluctuations in blood glucose levels can lead to loss of consciousness in animals. Both hyperglycemia and hypoglycemia can lead to diabetic coma, which is characterized by disorientation and convulsions. Diabetic coma is a life-threatening event. Without therapy of diabetic rats, blood glucose levels rising significantly, there is dehydration and electrolyte losses by urine, is not stores the fat and protein, even significantly break down protein and fat reserves. This dysregulation leads to ketosis and the release of ketone bodies in blood. It is unethical not treated animals with glycemia above $25 \mathrm{mM} / \mathrm{L}$. Therefore, certain authors rejected animals from experiment with glycemia above $25 \mathrm{mM} / \mathrm{L}$ (Matteucci \& Giampietro, 2008).

Similarly, non-treatment of significant hypoglycemia in the initial phase of alloxan diabetes is unethical. Some authors reported that animals are treated by glucose solution to alleviate complications and death due to hypoglycemia during the first 6 hours after administration of alloxan (de Carvalho et al., 2008). 
Induction of diabetes after administration of diabetogenic substances is confirmed by the determination of glucose in blood. After blood collection are blood cells separated within one hour with the addition of glycolytic inhibitors. Glucose is then determined in plasma by using of standard enzymatic methods (Sacks et al., 2002). The concentration of glucose in plasma is $11 \%$ higher than in whole blood and glucose concentration in heparinized plasma may be $5 \%$ lower than in serum. Glucose concentrations during the oral glucose tolerance test in capillary blood are higher (about 20-25\%) than in venous blood. Variation coefficient for glucose in plasma is $\leq 2.2 \%$. Transmissible glucometers have a much lower sensitivity than the above coefficient of variation. There are similar differences between values measured by different glucometers. American Diabetes Association has built a development goal for blood glucose monitors with analytical deviations $<5 \%$. The diagnosis of diabetes in humans is based on the following criteria (ECDCDM, 2003):

- $\quad$ symptoms of diabetes and casual glycemia above $11.1 \mathrm{mM} / \mathrm{L}$;

- fasting glycemia (FPG, Fasting Plasma Glucose) $\geq 7.0 \mathrm{mM} / \mathrm{L}$;

- $\quad$ glycemia after glucose load increases over $2 \mathrm{~h} \geq 11.1 \mathrm{mM} / \mathrm{L}$.

These values can be confirmed the next day by re-examination. It must be noted that these criteria are applicable if the rules for determining the glucose levels are sufficiently accurate and sensitive beyond the range of between 7 and $11.1 \mathrm{mM} / \mathrm{L}$.

When using the blood glucose monitors is needed just a drop of blood (less traumatized animals), although reproducibility and statistical accuracy is lower (needs more tests). As is to harmonize with the principle of the four R?

Oral glucose tolerance test (oGTT) provides information on ability to cope with the load by glucose. In adults, it is used in 3 hours arrangement and applied to $100 \mathrm{~g}$ of glucose in the diagnosis of gestational diabetes mellitus, compared with 2 hours arrangement and the application of $75 \mathrm{~g}$ glucose was used to confirm a diagnosis of diabetes (prediabetes) in the previous dubious blood glucose levels. In children used $1.75 \mathrm{~g}$ glucose $/ \mathrm{kg}$ of b.w. maximum of $75 \mathrm{~g}$ glucose. It is a sensitive test for detection of disorders of glucose metabolism, especially if fasting blood glucose are in the dubious areas. For its correct implementation is necessary to respect a several principles:

- does not reduce the glucose uptake three days before the test;

- $\quad$ test should be performed after fasting overnight (10-14 h);

- $\quad 25-30 \%$ glucose solution is administered orally;

- glucose levels are measured before and 30,60 and 120 minutes after administration of glucose;

- during the test do not receive food and water.

In rats given $25-30 \%$ aqueous solution of anhydrous glucose at a dose of $1-10 \mathrm{~g} / \mathrm{kg}$ of b.w. Sampling are quite different before glucose administration and every 30 minutes up to 300 minutes after glucose administration (Matteucci \& Giampietro, 2008). 
In rats, it would be appropriate to use a similar arrangement of the test than in children with a completed at $120 \mathrm{~min}$, in the case of dubious glucose levels at $8-12 \mathrm{mM} / \mathrm{L}$.

If in rats are found blood glucose levels (between $12-16 \mathrm{mM} / \mathrm{L}$ ), they can be considered as mild diabetic (or as prediabetic condition). Usually they have after a short period increased blood glucose above $16 \mathrm{mM} / \mathrm{L}$, rats with glycemia above this level are considered as clearly diabetic (Lukačínová et al., 2008).

In the oGTT in rats and humans is difference in glucose load in terms of $1 \mathrm{~kg}$ of body weight. These differences are not indicated anything substantial cause.

Intravenous glucose tolerance test (ivGTT) used to determine of insulin secretion and determination of the first phase of insulin response (FPIR, First Phase Insulin Response), which is considered a risk factor for T1D in humans (Culina et al., 2011). When studying the prevention of T1D showed that $2 \mathrm{~h}$ oGTT was sensitive about 6 months before diagnosis of diabetes compared with FPIR, which was lower and declined with age. Higher sensitivity was achieved using both tests (Barker et al., 2007). Dextrose was administered at a dose of $0.5 \mathrm{~g} / \mathrm{kg}$ (maximum $35 \mathrm{~g}$ ) intravenously over 3 minutes. Blood was taken with the $-10,-4,1,3,5,7$ and 10 minutes before and after load with dextrose and analyzed for glucose and insulin. FPIR is expressed on the basis of the sum of values 1 and 3-minute insulin levels.

In rats, using anhydrous glucose at a dose of 0.001 to $1.0 \mathrm{~g} / \mathrm{kg}$ of b.w. and blood glucose and insulin are evaluated at different time periods typically from -15 min within 30-120 minutes from the load with glucose. It should be noted that these tests in animals do not have such importance and predictive value as in humans (mainly the system of food intake and fasting before the test). Deprivation of food in animals from the evening before the examination is a powerful stress stimulus (due to their nocturnal activity), which has a significant influence on interindividual differences. Of course it is difficult to determine what dose of load in humans corresponds to a similar stress in rats, what is the possibility of extrapolation of results between these species. Probably there should be a $35 \mathrm{~g}$ aliquot of the maximum load in humans (but how and when to realize?). We believe that this model could be accepted to study of impact assessment of preventive or therapeutically active substances.

Intraperitoneal glucose tolerance test (ipGTT) is not used in humans. In rats, the dose of glucose ranging from 0.2 to $2.0 \mathrm{~g} / \mathrm{kg}$ of b.w. and monitored for three to seven time periods from 0 to 60-120 minutes after load of glucose (Matteucci \& Giampietro, 2008). It should therefore be considered only as an experimental model without real impact for extrapolation. This model may be interesting for studies comparing of load by different agents as a possible methodological model.

When studying the problem of diabetes plays an experimental protocol and the possibility of extrapolating a very important role. The experimental protocol must include a detailed description of the methods of research, in an experiment to be included animals suitable for this study and must be chosen a good system of controls, 
used substances must be best defined and used appropriate methods of statistical analysis of results. E.g., in the case of research in herbal medicine has been submitted WHO guidelines specifying the some principles of experiment (WHO, 1993). The primary aims of non-clinical studies are: (1) determine whether the substance has a beneficial effect in terms of herbal medicine (2) characterize the range of pharmacological effects, (3) define the chemical characteristics of the pharmacologically active natural products and their mechanisms of action.

Pharmacodynamic and current pharmacological investigations used animal models or bioassays which are good models for modeling of human disease. As an experimental object (test system) can be used live animals, isolated organs or tissues, blood and its components, tissue and cell cultures, and various subcellular structures. A very important point is determining the appropriate doses for a given system from viewpoints of study of dose-effect relationship and their extrapolation to human (Resjö et al., 2008). In all studies must be a negative control (vehicle without active substance) and positive control (known drug/substance). The series of examinations should be tests to clarify the biological activity of the herbal preparation. For example, plasma insulin concentrations in relation to blood glucose, liver glycogen and triglyceride levels may help in understanding the absorption and utilization of glucose and the like. Toxicological methods include tests of toxicity (topical, systemic and special). Acute toxicity tests require a sufficient number of dose levels to determine the lethal dose and monitoring should take at least 7-14 days. In chronic tests of toxicity is application period lasts from the 2 weeks to 12 months. Particularly difficult are lifelong toxicity tests (Lukačínová et al., 2011). When rodents are used it is recommended that each group has at least 5-10 animals for both sexes.

In most animal studies, the experimenters assessed the effect of intervention on the basis of the null hypothesis, i.e. assume that the experimental intervention had no effect. Guidelines for construction of animal experiments is why strictly rules necessary for adequate control by using the smallest number of animals (Festing \& Altman, 2002). Randomization and the use of blanks are rarer and therefore animal experiments indicate much more positive effects of treatment (Perel et al., 2007). Random choice of animals is essential for selection of animals to experimental (treated) and control groups (usually all individuals are healthy!) and despite does not reflect adequately to human population. Groups are designated by researcher and he knew what was that group treated and has been these groups intervened. In this area, animal experiments will be necessary to objectify (one divided and treated groups, and other these groups evaluated).

Since safety and efficacy of drugs before clinical examination are tested on animals, there are important all efforts to eliminate bias and random errors. Moreover, animal models should be as much as possible related clinical conditions. This is particularly important in extrapolation of dose $\left(\mathrm{g} / \mathrm{kg}, \mathrm{g} / \mathrm{m}^{2}\right.$ of body surface, resp.). Similarly, when comparing in drug already in use, in animal experiments should be used of dosage as in humans. 


\title{
5. Conclusion
}

The dawn and the subsequent development of experimental medicine in the second half of the XIXth century was unimaginable without the use of animals. Nobody cared about their fate and suffering - they were sacrificed in the war against diseases and for the development of science. The rules of experiment were simple and represented only the needs of the experimentator. The discovery of pancreatic diabetes and the subsequent isolation of insulin are the best examples of this era.

The situation changed dramatically in the second half of the XXth century in the development of new methods on laboratory analysis, in the development of new preventive and therapeutic procedures but especially in the new non-animal and animal models for the study in this area. For this analysis shows that are not yet standardized animal experiments even in the study of diabetes. These differences can lead to different conclusions regarding the pharmacologically active substances used in particular in the prevention but also in treatment of diabetes mellitus, e.g., hypoglycemic effect and dose relations in the application of vanadium or bioflavonoids (Lukačínová et al., 2008). It will be important to present a unified experimental approaches for testing of different substances on animals, both from the aspect of arrangement the experiment (control groups, conditions of experiment, statistical evaluation) as well as the selection of the studied parameters (markers) for individual type of test (acute, chronic, etc.) or the test substance. In this consideration is necessary increased attention to the requirements for the application of $4 \mathrm{R}$. In this case, it can be expected the significant reduction in the need for experimental animals, does not need to repeat certain experiments only because they were not considered some of the basic conditions (often simple parameters such as the weight of the animals, water intake, food intake, urine output, etc.). Therefore, further work is needed to improve and refine existing guidelines for their specific needs for testing of biologically active substances for medical use. Especially at present when more and more come to the forefront of evidence-based medicine (Borgerson, 2005) should become a standard working method in animal experiments.

In any case, in the future is expected many new findings from animal models, particularly in the pathogenesis of human diseases. The immediate benefit of such experiments was the introduction to testing of insulin therapy, as well as testing of other drugs. It is necessary to calculate that there can also lead to no thoroughfares of research, and it should be remembered the reproducibility and extrapolation of results for the human population. We expect the most benefit but in the verification of preventive strategies with various drugs.

\section{Author details}

\author{
A. Lukačínová \\ Department of Physiology, Faculty of Medicine, Šafárik University, Košice, Slovak Republic \\ B. Hubková \\ Department of Medical and Clinical Biochemistry, \\ Faculty of Medicine, Šafárik University, Košice, Slovak Republic
}


O. Rácz

Department of Pathological Physiology,

Faculty of Medicine, Šafárik University, Košice, Slovak Republic

Department of Nanobiotechnology and Regenerative Medicine,

Faculty of Healthcare, Miskolc University, Hungary

F. Ništiar

Department of Pathological Physiology,

Faculty of Medicine, Šafárik University, Košice, Slovak Republic

\section{Acknowledgement}

This work was supported by Grant Agency VEGA No. 1/3494/06.

\section{References}

Aerts, L., Van Assche, F.A. (2006): Animal evidence for the transgenerational development of diabetes mellitus. Intern. J. Biochem. Cell Biol., vol. 38, No. 3-4 (May-June 2006), pp. 894-903. ISSN 1357-2725.

Atkinson, M.A., Eisenbarth, G.S. (2001): Type 1 diabetes: New perspectives on disease pathogenesis and treatment. Lancet, vol. 358, No. 9277 (21 July 2001), pp. 221-229. ISSN 0140-6736.

Atkinson, M.A., Leiter, E.H. (1999): The NOD mouse model of insulin dependent diabetes: As good as it gets? Nature Med., vol. 5, No. 6 (June 1999), pp. 601-604. ISSN 1078-8956.

Bark, R.E. (1995): The fourth R of research. Am. Assoc. Lab. Anim. Sci., Vol. 54, No. 2 (March 1995), p. 50. ISSN 1559-6109

Barker, J.M., McFann, K., Harrison, L.C., Fourlanos, S., Krischer, J., Cuthbertson, D., Chase, H.P., Eisenbarth, G.S. (2007): Pre-type 1 diabetes dysmetabolism: maximal sensitivity achieved with both oral and intravenous glucose tolerance testing. J. Pediatrics, Vol. 150, No. 1 (January 2007), pp. 31-36. ISSN 0340-6199

Benoist, C., Mathis, D. (1997): Autoimmune diabetes: Retrovirus as trigger, precipitator or marker? Nature, Vol. 388, No. 6645 (28 August 1997), pp. 833-834. ISSN 0028-0836

Berdanier, C.D. (2007): Linking mitochondrial function to diabetes mellitus: an animal's tale. Am. J. Physiol. Cell Physiol., Vol. 293, No. 3 (September 2007), pp. C830-C836. ISSN 03636143

Beynen, A.C., Hau, J. (2001): Animal models. In: Principles of Laboratory Animal Science. van Zutphen, L.F.M., Baumans, V., Beynen, A.C. (Eds): Principles of Laboratory Animal Science. Elsevier, ISBN 0444506128, Amsterdam, pp. 197-205.

Blas, E., Sivasankara Kurup, A. (Eds.) (2010): Priority Public Health Conditions: From Learning to Action on Social Determinants of Health. World Health Organization, ISBN 9789241563970, Geneva, pp. 77-94.

Bliss, M. (1982): The discovery of insulin. Chicago Univ. Press, ISBN 0-226-05897-2, Chicago, pp. 1-304. 
Bonora, E. (2008): Protection of pancreatic beta-cells: is it feasible? Nutr. Metab. Cardiovasc. Dis., Vol. 18, No. 1 (January 2008), pp. 74-83. ISSN 0939-4753

Borgerson, K. (2005): Evidence-Based Alternative Medicine? Perspect. Biol. Med., Vol. 48, No. 4 (Autumn 2005), pp. 502-515. ISSN 0031-5982

Brownlee, M. (2001): Biochemistry and molecular cell biology of diabetic complications. Nature, Vol. 414, No. 6865 (13 December 2001), pp. 813-820. ISSN 0028-0836

Bucala, R., Makita, Z., Koschinsky, T., Cerami, A., Vlassara, H. (1993): Lipid advanced glycosylation: pathway for lipid oxidation in vivo. Proc. Natl. Acad. Sci. USA, Vol. 90, No. 14 (15 July 1993), pp. 6434-6438. ISSN 0027-8424

Bucala, R., Vlassara, H., Cerami, A. (1994): Advanced glycosylation end products: role in diabetic and non-diabetic vascular disease. Drug Develop. Res., Vol. 32, No. 2 (June 1994), pp. 77-89. ISSN 1098-2299

Carlsson, P.-O., Palm, F., Andersson, A., Liss, P. (2000): Chronically decreased oxygen tension in rat pancreatic islets transplanted under the kidney capsule. Transplantation, Vol. 69, No. 5 (15 March 2000), pp. 761-766. ISSN 0041-1337

Calabrese, E.J. (1991): Principles of Animal Extrapolation: Predicting Human Responses from Animal Studies. Lewis Publishers, Inc., ISBN 0-87371-410-5, Chelsea, MI., pp. 1-616.

Caluwaerts, S., Holenmans, K., Van Bree, R., Verhaeghe, J., Van Assche, F.A. (2003): Is lowdose streptozotocin in rats an adequate model for gestational diabetes mellitus? J. Soc. Gynecol. Investig., Vol. 10, No. 4 (May 2003), pp. 216-221. ISSN 1071-5576

Carvalho, V.F., Campos, L.V., Farias-Filho, F.A., Florim, L.T., Barreto, E.O., Pirmez, C., Savino, W., Martins, M.A., Silva, P.M.R. (2008): Suppression of allergic inflammatory response in the skin of alloxan-diabetic rats: relationship with reduced local mast cell numbers. Int. Arch. Allergy Immunol., Vol. 147, No. 3 (October 2008), pp. 246-254. ISSN 1018-2438

Cefalu, W.T. (2006): Animal models of type 2 diabetes: clinical presentation and pathophysiological relevance to the human condition. ILAR J., Vol. 47, No. 3, pp. 186198. ISSN 1084-2020

Culina, S., Boitard, C., Mallone, R. (2011): Antigen-based immune therapeutics for type 1 diabetes: magic bullets or ordinary blanks? Clin. Develop. Immunol., doi:10.1155/2011/286248. ISSN 1740-2522

Dell, R.B., Hollevan, S., Ramakrishnan, R. (2002): Sample size determination. ILAR J., Vol. 43, No. 4, pp. 207-213. ISSN 1084-2020

Dong, W., Shil, H.B., Ma, H., Miao, Y.B., Liu, T.J., Wang, W. (2010): Homoisoflavanones from Polygonatum odoratum rhizomes inhibit advanced glycation end product formation. Arch. Pharm. Res., Vol. 33, No. 5 (May 2010), pp. 669-674. ISSN 0253-6269

Dyer, D.G., Blackledge, J.A., Thorpe, S.R., Baynes, J.W. (1991): Formation of pentosidine during nonenzymatic browning of proteins by glucose. J. Biol. Chem., Vol. 266, No. 18 (25 June 1991), pp. 11654-11660. ISSN 0021-9258

Eiselein, L., Schwartz, H.J., Rutledge, J.C. (2004): The challenge of type 1 diabetes mellitus. ILAR J., Vol. 45, No. 3, pp. 231-236. ISSN 1084-2020

Ettaro, L., Songer, T.J., Zhang, P., Engelgau, M.M. (2004): Cost-of-illness studies in diabetes mellitus. Pharmacoeconomics, Vol. 22, No. 3, pp. 149-164. ISSN 1170-7690 
ECDCDM (Expert Committee on the Diagnosis and Classification of Diabetes Mellitus) (2003): Report of the expert committee on the diagnosis and classification of diabetes mellitus. Diabetes Care, Vol. 26, Suppl. 1 (January 2003), pp. S5-S20. ISSN 0149-5992

Festing, M.F.W., Altman, D.G. (2002): Guidelines for the design and statistical analysis of experiments using laboratory animals. ILAR J., Vol. 43, No. 4, pp. 244-258. ISSN 10842020

Franconi, F., Seghieri, G., Canu, S., Straface, E., Campesi, I., Malorni, W. (2008): Are the available experimental models of type 2 diabetes appropriate for a gender perspective? Pharmacol. Res., Vol. 57, No. 1 (January 2008). pp. 6-18. ISSN 1043-6618

Green, A., Patterson, C.C., EURODIAB TIGER SG (2001): Trends in the incidence of childhood-onset diabetes in Europe 1989-1998. Diabetologia, Vol. 44, Suppl. 3 (October 2001), pp. B3-B8. ISSN 0012-186X

Greiner, D.L., Rossini, A.A., Mordes, J.P. (2001): Translating data from animal models into methods for preventing human autoimmune diabetes mellitus: caveat emptor and primum non nocere. Clin. Immunol., Vol. 100, No. 2 (August 2001), pp. 134-143. ISSN 1521-6616

Harder, T., Franke, K., Fahrenkrog, S., Aerts, L., Van Bree, R., Van Assche, F.A., Plagemann, A. (2003): Prevention by maternal pancreatic islet transplantation of hypothalamic malformation in offspring of diabetic mother rats is already detectable at weaning. Neurosci. Lett., Vol. 352, No. 3 (11 December 2003), pp. 163-166. ISSN 0304-3940

Hau, J. (2008): Animal models for human disease: an overview. In: Sourcebook of Models for Biomedical Research. Conn, M.P. (Ed.): Humana Press, ISBN 978-1-58829-933-8, Totowa, New Jersey, pp. 3-8.

Hau, J., Poulsen, O.M. (1988): Doses for laboratory animals based on metabolic rates. Scand. J. Lab. Anim. Sci., Vol. 15, No. 2, pp. 81-84. ISSN 0901-3393

Herrera, E., Palacin, M., Martin, A., Lasuncion, M.A. (1985): Relationship between maternal and fetal fuels and placental glucose transfer in rats with maternal diabetes of varying severity. Diabetes, Vol. 34, Suppl. 2, pp. 42-46. ISSN 0012-1797

Junod, A., Lambert, A. E., Stauffacher, W. and Renold, A. E. (1969): Diabetogenic action of streptozotocin: Relationship of dose to metabolic response. J. Clin. Invest., Vol. 48, No. 11 (1 November 1969), pp. 2129-2139. ISSN 0021.9738

Kaplan, J.R., Wagner, J.D. (2006): Type 2 diabetes - an introduction to the development and use of animal models. ILAR J., Vol. 47, No. 3, pp. 181-185. ISSN 1084-2020

Kaufman, D.L., Erlander, M.G., Clare-Salzler, M., Atkinson, M.A., Maclaren, N.K., Tobin, A.J. (1992): Autoimmunity to two forms of glutamate decarboxylase in insulindependent diabetes mellitus. J. Clin. Invest., Vol. 89, No. 1 (1 January 1992) pp. 283-292. ISSN 0021.9738

Kobayashi, T., Arefanian, H., Harb, G., Tredget, E.B., Rajotte, R.V., Korbutt, G.S., Rayat, G.R. (2008): Prolonged survival of microencapsulated neonatal porcine islet xenografts in immune-competent mice without antirejection therapy. Cell Transplant., Vol. 17, No. 11/12, pp. 1243-1256. ISSN 0963-6897

Koppányi, T., Avery, M.A. (1966): Species differences and the clinical trial of new drugs: a review. Clin. Pharmacol. Ther., Vol. 7, No. 2 (February 1966), pp. 250-270. ISSN 0009-9236 
Korec, R. (1991): Experimental and Spontaneous Diabetes Mellitus in the Rat and Mouse. Edition Center of Šafarik University, ISBN 80-7097-123-1, Košice, pp. 1-248.

Kukreja, A., Maclaren, N.K. (1999): Autoimmunity and diabetes. J. Clin. Endocrinol. Metab., Vol. 84, No. 12 (1 December 1999), pp. 4371-4378. ISSN 0021-972X

Lanza, R.P., Ecker, D.M., Kühtreiber, W.M., Marsh, J.P., Ringeling, J., Chick, W.L. (1999): Transplantation of islets using microencapsulation: studies in diabetic rodents and dogs. J. Molecular Medicine, Vol. 77, No. 1 (January 1999), pp. 206-210. ISSN 0946-2716

Lee, G.H., Proenca, R., Montez, J.M., Carroll, K.M., Darvishzadeh, J.G., Lee, J.I., Friedman, J.M. (1996): Abnormal splicing of the leptin receptor in diabetic mice. Nature, Vol. 379, No. 6566 (15 February 1996), pp. 632-635. ISSN 0028-0836

Leiter, E.H. (1998): NOD mice and related strains: Origins, husbandry, and biology. In: NOD Mice and Related Strains: Research Applications in Diabetes, AIDS, Cancer and Other Diseases. Leiter, E.H., Atkinson, M.A. (Eds.): Internet: R.G. Landes Co., ISBN 157059466X, pp. 1-36.

Leiter, E. H., von Herrath, M. (2004): Animal models have little to teach us about type 1 diabetes: 2. In opposition to this proposal. Diabetologia, Vol. 47, No. 10 (October 2004), pp. 1657-1660. ISSN 0012-186X

Lenzen, S. (2008): The mechanisms of alloxan- and streptozotocin-induced diabetes. Diabetologia, Vol. 51, No. 2 (February 2008), pp. 216-226. ISSN 0012-186X

Lenzen, S., Panten, U. (1988): Alloxan: history and mechanism of action. Diabetologia, Vol. 31, No. 6 (June 1988), pp. 337-342. ISSN 0012-186X

Loew, F.M. (1996): Using animals in research. In: Birth to Death: Science and Bioethics. Thomasma, D.C., Kushner, T. (Eds): Cambridge University Press, ISBN 0521555566, Cambridge, pp. 301-312.

Lotfy, M., Singh, J., Kalász, H., Tekes, K., Adeghate, E. (2011): Medicinal chemistry and applications of incretins and DPP-4 inhibitors in the treatment of type 2 diabetes mellitus. Open Med. Chem. J., Vol. 5, Supple 2-M4 (9 September 2011), pp. 82-92. ISSN 1874-1045

Lukačínová, A., Mojžišs, J., Beňačka, R., Keller, J., Maguth, T., Kurila, P., Vaško, L., Rácz, O., Ništiar, F. (2008): Preventive effects of flavonoids on alloxan-induced diabetes mellitus in rats. Acta Vet. Brno, Vol. 77, No. 2 (June 2008), pp. 175-182. ISSN 0001-7213

Lukačínová, A., Rácz, O., Lovásová, E., Ništiar, F. (2011): Effect of lifetime low dose exposure to heavy metals on selected serum proteins of Wistar rats during three subsequent generations. Ecotoxicol. Environ. Saf., Vol. 74, No. 6 (September 2011), pp. 1747-1755. ISSN 0147-6513

Mann, R. D. (1984): Modern Drug Use; An Enquiry on Historical Principles. MTP Press Ltd., ISBN 0852007175, Lancaster and London, pp. 1-769.

Matteucci, E., Giampietro, O. (2008): Proposal open for discussion: defining agreed diagnostic procedures in experimental diabetes research. J. Ethnopharm., Vol. 115, No. 2 (17 January 2008), pp. 163-172. ISSN 0378-8741

McNamara, J.M., Stephens, P.A., Dall, S.R.X., Houston, A. I. (2009): Evolution of trust and trustworthiness: social awareness favours personality differences. Proc. R. Soc. B, Vol. 276, No. 1657 (22 February 2009), pp. 605-613. ISSN 1471-2954 
Miller, M.T., Strömland, K. (1999): Teratogen update: Thalidomide: a review, with a focus on ocular findings and now potentional uses. Teratology, Vol. 60, No. 5 (November 1999), pp. 306-321. ISSN 1542-0760

Minkowski, O. (1989): Historical development of the theory of pancreatic diabetes. Diabetes, Vol. 38, No. 1 (January 1989), pp. 1-6. ISSN 0012-1797

Mordes, J.P., Bortell, R., Groen, H., Guberski, D.L., Rossini, A.A., Greiner, D.L. (2001): Autoimmune diabetes mellitus in the BB rat. In: Animal Models of Diabetes: A Primer. Sima, A.A.F., Shafrir, E. (Eds.). Harwood Academic Publishers, ISBN 9058230961, Warsaw, pp. 1-41.

Ništiar, F., Ništiarová, A., Beňačka, R., Rácz, O., Lukačínová, A. (2006): Quo vadis experiments on animals in the university education and tesearch? Slovak Veter. J., Vol. 31, No. 5, pp. 289-291. ISSN 1335-0099

Ohgami, N., Nagai, R., Ikemoto, M., Arai, H., Kuniyasu, A., Horiuchi, S., Nakayama, H. (2001): Cd36, a member of the class b scavenger receptor family, as a receptor for advanced glycation end products. J. Biol. Chem., Vol. 276, No. 2 (2 February 2001), pp. 3195-3202. ISSN 0021-9258

Olson, H., Betton, G., Robinson, D., Thomas, K., Monro, A., Kolaja, G., Lilly, P., Sanders, J., Sipes, G., Bracken, W., Dorato, M., Van Deun, K., Smith, P., Berger, B., Heller. A. (2000): Concordance of the toxicity of pharmaceuticals in humans and in animals. Regul. Toxicol. Pharmacol., Vol. 32, No. 1 (August 2000), pp. 56-67. ISSN 0273-2300

Peppa, M., Uribarri, J., Vlassara, H. (2004): The role of advanced glycation end products in the development of atherosclerosis. Curr. Diabetes Rep., Vol. 4, No. 1 (February 2004), pp. 31-36. ISSN 1534-4827

Perel, P., Roberts, I., Sena, E., Wheble, P., Briscoe, C., Sandercock, P., Macleod, M., Mignini, L.E., Jayaram, P., Khan, K.S. (2007): Comparison of treatment effects between animal experiments and clinical trials: systematic review. BMJ, Vol. 334, No. 7586 (27. January 2007), pp. 197-202. ISSN 0959-8138

Perry, P. (2007): The ethics of animal research: a UK perspective. ILAR J., Vol. 48, No. 1, pp. 42-46. ISSN 1084-2020

Quehenberger, P., Bierhaus, A., Fasching, P., Muellner, C., Klevesath, M., Hong, M., Stier, G., Sattler, M., Schleicher, E., Speiser, W., Nawroth, P.P. (2000): Endothelin-1 transcription is controlled by nuclear factor-kappa B in AGE-stimulated cultured endothelial cells. Diabetes, Vol. 49, No. 9 (September 2000), pp. 1561-1570. ISSN 00121797

Rees, D.A., Alcolado, J.C. (2005): Animal models of diabetes mellitus. Diabetic Medicine, Vol. 22, No. 4 (April 2005), pp. 359-370. ISSN 1464-5491

Resjö, R., Berger, K., Fex, M., Hansson, O. (2008): Proteomic studies in animal models of diabetes. Proteomics Clin. Appl., Vol. 2, No. 5 (5 May 2008), pp. 654-669. ISSN 1862-8354

Roglic, G., Unwin, N. (2010): Mortality attributable to diabetes: estimates for the year 2010. Diabetes Res. Clin. Pract., Vol. 87, No. 1 (January 2010), pp. 15-19. ISSN 0168-8227

Rossini, A.A., Thompson, M.J., Mordes, J.P. (2003): Diabetes mellitus. In: Office Practice of Medicine. 4th ed., Branch, W.T. Jr. (Ed.): Saunders, ISBN 0721676723, Philadelphia, pp. 695-740. 
Russell, W.M.S., Burch, R.L. (1959): The Principles of Humane Experimental Technique. Methuen \& Co. Ltd., ISBN 0900767782, London, pp. 1-238.

Sacks, D.B., Bruns, D.E., Goldstein, D.E., Maclaren, N.K., McDonald, J.M., Parrott, M. (2002): Guidelines and recommendations for laboratory analysis in the diagnosis and management of diabetes mellitus. Clin. Chem., Vol. 48, No. 3 (March 2002), pp. 436-472. ISSN 1434-6621

Salgado, H.C., Fazan, R., Fazan, V.P.S., Dias da Silva, V.J., Barreira, A.A. (2001): Arterial baroreceptors and experimental diabetes. Ann. N. Y. Acad. Sci., Vol. 940, No. 1 (September 2001), pp. 20-27. ISSN 1749-6632

Sandow, J. (2009): Growth effects of insulin and insulin analogues. Arch. Physiol. Biochem., Vol. 115, No. 2 (May 2009), pp. 72-85. ISSN 1744-4160

Semple, R.K., Savage, D.B., Cochran, E.K., Gorden, P., O'Rahilly, S. (2011): Genetic syndromes of severe insulin resistance. Endocr. Rev., Vol. 32, No. 4 (1 August 2011), pp. 498-514. ISSN 0163-769X

Serreze, D.V., Leiter, E.H. (2001): Genes and pathways underlying autoimmune diabetes in NOD mice. In: Molecular Pathology of Insulin Dependent Diabetes Mellitus. Von Herrath M.G. (Ed.): Karger Press, ISBN 3805572409, Basel, pp. 31-67.

Shafrir, E. (2003): Diabetes in animals: contribution to the understanding of diabetes by study of its etiopathology in animal models. In: Diabetes Mellitus, Porte, D., Sherwin, R.S., Baron, A. (Eds.), McGraw-Hill, ISBN 0838520413, New York, pp. 231-255.

Shaw, J., Sicree, R., Zimmet, P. (2010): Global estimates of the prevalence of diabetes for 2010 and 2030. Diabetes Res. Clin. Pract., 87, pp. 4-14.

Sima, A.A.F., Shafrir, E. (Eds.) (2000): Animal Models of Diabetes: A Primer. Harwood Academic Publishers, ISBN 9058230961, Amsterdam, pp. 1-364.

Skyler, J.S., Brown, D., Chase, H.P., Collier, E., Cowie, C., Eisenbarth, G.S., Fradkin, J., Grave, G., Greenbaum, C., Jackson, R.A., Kaufman, F.R., Krischer, J.P., Marks, J.B., Palmer, J.P., Ricker, A., Schatz, D.A., Wilson, D., Winter, W.E., Wolfsdorf, J., Zeidler, A., Dickler, H., Eastman, R.C., Maclaren, N.K., Malone, J.I. (2002): Effects of insulin in relatives of patients with type 1 diabetes mellitus. N. Engl. J. Med., Vol. 346, No. 22 (30 May 2002). pp. 1685B-1691B. ISSN 0028-4793

Srinivasan, K., Ramarao, P. (2007): Animal models in type 2 diabetes research: an overview. Indian J. Med. Res., Vol. 125, No. 3 (March 2007), pp. 451-472. ISSN 0971-5916

Stern, D.M., Yan, S.D., Yan, S.F., Schmidt, A.M. (2002): Receptor for advanced glycation end products (RAGE) and the complications for diabetes. Ageing Res. Rev., Vol. 1, No. 1 (February 2002), pp. 1-15. ISSN 1568-1637

Suarez-Pinzon, W.L., Rabinovitch, A. (2001): Approaches to type 1 diabetes prevention by intervention in cytokine immunoregulatory circuits. Int. J. Exp. Diabetes Res., Vol. 2, No. 1, pp. 3-17. ISSN 1560-4284

Tesch, G. H., Nikolic-Paterson, D. J. (2006): Recent Insights into experimental mouse models of diabetic nephropathy, The Nephron Journals, Vol. 104, No. 2 (September 2006), pp. 5762. ISSN 1660-8151 
Tirabassi, R.S., Flanagan, J.F., Wu, T., Kislauskis, E.H., Birckbichler, P.J., Guberski, D.L. (2004): The BBZDR/Wor rat model for investigating the complications of type 2 diabetes mellitus. ILAR J., Vol. 45, No. 3, pp. 292-302. ISSN 1084-2020

Trimble, E.R., Siegel, E.G., Berthoud, H.-R., Renold, A.E. (1980): Intraportal islet transplantation: functional assessment in conscious unrestrained rats. Endocrinology, Vol. 106, No. 3 (1 March 1980), pp. 791-797. ISSN 0013-7227

Van der Werf, N., Kroese, F.G., Rozing, J., Hillebrands, J.L. (2007): Viral infections as potential triggers of type 1 diabetes. Diabetes Metab. Res. Rev., Vol. 23, No. 3 (March/April 2007), pp. 169-183. ISSN 1520-7552

Vaxillaire, M., Froguel, P. (2008): Monogenic diabetes in the young, pharmacogenetics and relevance to multifactorial forms of Type 2 diabetes. Endocr. Rev., Vol. 29, No. 3 (1 May 2008), pp. 254-264. ISSN 0163-769X

Vlassara, H. (1997): Recent progress in advanced glycation end products and diabetic complications. Diabetes, Vol. 46, Suppl. 2, pp. S19-S25. ISSN 0012-1797

Von Herrath, M., Nepom, G.T. (2009): Animal models of human type 1 diabetes. Nature Immunol., Vol. 10, No. 2 (February 2009), pp. 129-132. ISSN 1529-2908

Wada, R., Yagihashi, S. (2005): Role of advanced glycation end products and their receptors in development of diabetic neuropathy. Ann. N. Y. Acad. Sci., Vol. 1043, No. 1 (June 2005), pp. 598-604. ISSN 1749-6632

Wang, P., Yigit, M.V., Medarova, Z., Wei, L., Dai, G., Schuetz, C., Moore, A. (2011): Combined small interfering RNA therapy and in vivo magnetic resonance imaging in islet transplantation. Diabetes, Vol. 60, No. 2 (February 2011), pp. 565-571. ISSN 0012-1797

Wendt, T., Bucciarelli, L., Qu, W., Lu, Y., Yan, S.F., Stern, D.M., Schmidt, A.M. (2002): Receptor for advanced glycation endproducts (RAGE) and vascular inflammation: Insights into the pathogenesis of macrovascular complications in diabetes. Curr. Atheroscler. Rep., Vol. 4, No. 3 (May 2002), pp. 228-237. ISSN 1523-3804

Whiting, D., Unwin, N., Roglic, G. (2010): Diabetes: equity and social determinants. In: Priority Public Health Conditions: From Learning to Action on Social Determinants of Health. Blas, E., Sivasankara Kurup A. (Eds.). World Health Organization, ISBN 9789241563970, Geneva, pp. 77-94.

WHO (World Health Organization) (1993): Research Guidelines for Evaluating the Safety and Efficacy of Herbal Medicines. Regional Office for the Western Pacific, ISBN 9290611103, Manila, pp. 1-94.

Wild, S. Roglic, G., Green, A., Sicree, R., King, H. (2004): Global prevalence of diabetes: estimates for the year 2000 and projections for 2030. Diabetes Care, Vol. 27, No. 5 (May 2994), pp. 1047-1053. ISSN 0149-5992

Williams, G., Pickup, J.C. (2004): Handbook of Diabetes. $3^{\text {rd }}$ ed., Blackwell Publishing Ltd., ISBN 1405120525, Malden MA, pp. 1-288.

Yang, Y., Santamaria, P. (2006): Lessons of autoimmune diabetes from animal models. Clinic. Sci., Vol. 110, No. 6 (June 2006), pp. 627-639. ISSN 0143-5221

Zhang, Y., Proenca, R., Maffei, M., Barone, M., Leopold, L., Friedman, J.M. (1994): Positional cloning of the mouse obese gene and its human homologue. Nature (Lond.), Vol. 372, No. 6505 (1 December 1994), pp. 425-432. ISSN 0028-0836 